\title{
Placing Music Video: A new audiovisual modality
}

\author{
Transforming Cultures eJournal, \\ Vol. 4 No 1, April 2009 \\ http://epress.lib.uts.edu.au/journals/TfC
}

\section{Collin Chua ${ }^{1}$}

\begin{abstract}
Music, as Jacques Attali emphasises, "is a way of perceiving the world" (1985:4). Sarah Cohen also suggests that: "Individuals can use music as a cultural 'map of meaning', drawing upon it to locate themselves in different imaginary geographies... and to articulate both individual and collective identities" (1998: 286-287). Tia DeNora extends on this, pointing out that: "Music can be used as a device for the reflexive process of remembering/constructing who one is, a technology for spinning the apparently continuous tale of who one is" (DeNora 2000: 63). Music has served various integral social and cultural functions in human societies throughout history. It seems clear that as music has changed shape and form through the advent of various reproduction technologies, ${ }^{2}$ the ways in which we consume as well as produce music, and the shape and form of music-as-cultural map and music as way of perceiving the world, have also changed over time.

In his book The Sight of Sound, Richard Leppert points out: "Precisely because musical sound is abstract, intangible, and ethereal - lost as soon as it is gained the visual experience of its production is crucial... for locating and communicating the place of music and musical sound within society and culture" (1993: xx-xxi). This paper will focus on what Michel Chion describes as "a very influential new audiovisual form, the music video, which has opened the doors to infinite possibilities in representing relations between a voice and its source" (1999: 172). The paper argues that the contemporary articulation of music and images, built on "infinite possibilities in representing relations between a voice and its source", has come to shape a persuasive new audiovisual modality for "locating and communicating the place of music and musical sound within society and culture". In order to examine this new audiovisual modality, I will move away from a conventional approach based upon looking at music video in terms of its non-narrative structure, and instead propose a conceptual approach based on looking at music video in terms of its production of space. This line of discussion will be navigated not by providing close textual readings of various music videos, but rather by examining and theorising the music video as cultural $/$ media form.
\end{abstract}

\footnotetext{
${ }^{1}$ Collin Chua teaches at the University of New South Wales, Sydney.

2 Such as the invention of musical notation, the dissemination of sheet music, the emergence of acoustically prepared spaces, the arrival of the gramophone, the tape player, the Walkman, the CD, the iPod, the digitisation of music, downloadable music files, the proliferation of music videos, etc. (See, for example, Chanan, 1995, and Katz, 2004.)
} 


\section{Introduction}

Music, as Jacques Attali emphasises, "is a way of perceiving the world" (1985:4). Sarah Cohen also suggests that "[i]ndividuals can use music as a cultural 'map of meaning', drawing upon it to locate themselves in different imaginary geographies... and to articulate both individual and collective identities" (1998: 286-287). Tia DeNora extends on this, pointing out that: "Music can be used as a device for the reflexive process of remembering/constructing who one is, a technology for spinning the apparently continuous tale of who one is" (2000:63). Music has served various integral social and cultural functions in human societies throughout history. It seems clear that as music has changed shape and form through the advent of various reproduction technologies, ${ }^{3}$ the ways in which we consume as well as produce music, and the shape and form of music-as-cultural map and music as way of perceiving the world, have also changed over time.

In his book The Sight of Sound, Richard Leppert points out: "Precisely because musical sound is abstract, intangible, and ethereal - lost as soon as it is gained - the visual experience of its production is crucial... for locating and communicating the place of music and musical sound within society and culture" (1993: xx-xxi). This paper will focus on what Michel Chion describes as "a very influential new audiovisual form, the music video, which has opened the doors to infinite possibilities in representing relations between a voice and its source" (1999:172). The paper argues that the contemporary articulation of music and images, built on "infinite possibilities in representing relations between a voice and its source", has come to shape a persuasive new audiovisual modality for "locating and communicating the place of music and musical sound within society and culture”. In order to examine this new audiovisual modality, I will move away from a conventional approach based upon looking at music video in terms of its non-narrative structure, and instead propose a conceptual approach based on looking at music video in terms of its production of space. This line of discussion will be navigated not by providing close textual readings of various music videos, but rather by examining and theorising the music video as cultural/media form.

\footnotetext{
${ }^{3}$ Such as the invention of musical notation, the dissemination of sheet music, the emergence of acoustically prepared spaces, the arrival of the gramophone, the tape player, the Walkman, the CD, the iPod, the digitisation of music, downloadable music files, the proliferation of music videos, etc. (See, for example, Chanan, 1995, and Katz, 2004.)
} 


\section{Historicising the music video}

By looking at a history of the development of the music video form, we can gain some sense of how the fantasy spaces of music videos have evolved via an increasingly sophisticated fusion of music and images. The music video became permanently established as a media form on American cable television, with the debut of MTV in the USA on 1 August 1981, as a channel dedicated to the non-stop broadcast of music videos. Appropriately, the first video screened was The Buggles' 'Video Killed the Radio Star'. This provocative title insinuates that the music video is a case of the image working to reinforce its hegemony over sound, resulting in a space where image has purportedly 'killed' music as a primarily aural form, by providing a definitive visual experience of its production. Other cable channels followed, not only in the United States, but in other developing countries and then subsequently beyond. Music videos did not take long to become common currency, and the spread of television and video helped play an important part in increasing the accessibility of music.

Initially, music videos were often recordings of live performances, but subsequently as the form evolved, more sophisticated, imaginative, and innovative concepts, imagery, effects, action sequences, and editing styles began to infuse music videos, as late-night and overnight television, and a growing number of TV stations, increased access and available time. Kay Dickinson (2007: 20) points out that in

the first half of the $1980 \mathrm{~s} . .$. there was an accelerated airing of pop promos on television. It was at this point that music video not only came into its own by becoming pretty much essential in the promotion of a mainstream hit, but also was in the process of working out its stylistic conventions."4

Connell and Gibson note that: "The establishment of MTV in Asia in 1992 (with a potential market of over a quarter of the world's population) emphasised the extent of globalisation and standardisation, and the role of image" (2003: 61).

The imagery found in music video is largely built along non-narrative forms; music video is not founded on traditional classical Hollywood narrative models, but rather can

\footnotetext{
4 Peter Gabriel's 'Sledgehammer' (1986, directed by Stephen R. Johnson) is a significant clip, as it arguably signals the music video's growth into artistic maturity. Using drawing, painting, Claymation, stop-motion animation, fruit collages, and post-production FX, the award-winning clip in many ways extended the formerly limited palette of the music video form.
} 
be defined as an assemblage of images, loosely ordered around various themes - in this sense, it remains closer to being a postmodern 'cinema of attractions' (Gunning). In its contemporary form, it has been impacted by a number of technological innovations. In coming to the forefront in the early $1990 \mathrm{~s}$, the spectacular computer-generated imagery (CGI) featured in Hollywood genre films "became an object of intense fascination, curiosity, and scrutiny in the popular and mass media" (Pierson 2002:3). ${ }^{5}$ A fondness for visual effects did not take long to make its way into the music video form. Computer-based non-linear editing systems, developed in the late 1980s, were also introduced in the early 1990s and within a few short years came to dominate postproduction. Digital media for sound recording and processing also quickly become the norm. This introduction of digital editing systems arguably marks the most significant change ever to have occurred in film-editing practice. The adoption of digital non-linear editing systems has changed the way moving images are viewed and assembled into sequences, influencing new kinds of assemblages, new perspectives on montage, and faster rhythms.

By the early-to-mid-1990s, as Roger Beebe states, "MTV ha[d] become a profoundly auteurist medium" (2007: 310). The imagery of music videos had been developed to the point where there were many ways of following a song. Vernallis comments that the imagery in music videos often reflects musical structure and can "pick up on specific musical features in the domains of melody, rhythm, and timbre. The image can even seem to imitate sound's ebb and flow and its indeterminate boundaries." Facilitated by "technological advances, such as video editing, digitisation, and new pre- and postproduction techniques, the image has become, as Michel Chion suggests, as voluble as speech." The various techniques developed by video-makers for putting image to music have meant that "the image gains in flexibility and play, as well as in polyvalence of meaning. Many of the meanings of music video lie in this give and take between sound and image and in the relations among their various modes of continuity" (Vernallis 2007: 112).

A new filmic 'language' has evolved for the fledgling form of music video. As a video unfolds, our attention shifts continually among music, image, and lyrics, as each

\footnotetext{
${ }^{5}$ Tom Gunning has termed this trend "the Spielberg-Lucas-Coppola cinema of effects", (Gunning 1990: $67)$.
} 
provides novelty at some point and then recedes into the background. This competition among various elements helps us understand the look of music video. The image can guide our attention from one musical feature to another. The spectacular rhetoric of images, the ambiguousness and repeatability, the intertextual references, the sampling and borrowing from other cinematic and televisual sources - have come to be characteristic of the audiovisual vocabulary developed by the music video form. A generational shift has also taken place in conjunction with the development of the music video form, where people have now grown up watching music videos, which have come to be more than simply performance videos, and who now accept it as normal for music to be accompanied by its video clip - nowadays, people have come to expect music to be paired with images, to understand and expect to consume music in terms of images. The music video form has become a site for new types of spaces, made possible by the malleability and fluidity of images, fused together and articulated with the music. These spaces, of course, contain bodies, which can be said to be in many ways moved by and marked by the music and the musicalised spaces they find themselves within.

Although many television and cable channels formerly devoted to playing music videos have decided to alter their programming away from playing non-stop music video clips, the music video form is by no means experiencing its demise. It is clear that with the rapid development of technology, music video has seen a tremendous explosion beyond the narrow limits of 'music television'. As Middleton and Beebe tell us, "music video has in actuality... enjoyed a major renaissance by circulating in a number of other places and other media" (2007: 1). They write:

Music videos have started showing up in forms that belie the confusion of music video (as a form) and music television (as a delivery technology for that form): music videos now come to us on DVDs and enhanced CDs; on PDAs, cell phones, and other wireless communication devices; and, perhaps most importantly, on the internet (2007: 2-3).

Of course, the music video form has had a widespread and clearly discernible influence and legacy on audiovisual forms more generally. Music video techniques and editing styles have been re-appropriated by the advertising industry and by mainstream filmmakers. The already hazy boundary between music video and advertisement has grown even hazier, with a range of music superstars shooting video-like advertisements for big corporations (such as Pepsi). The rise to Hollywood prominence of ad- and 
video-trained directors (like Ridley Scott, David Fincher, and Brett Ratner), and the arrival of a new generation of MTV-influenced film school graduates, means that music video's aesthetic has become integrated into the mainstream. At the same time, and largely as a result of its influence, music videos have also come to repeat banal clichés. While there is a tremendous range of music videos produced in various locations in the world, what is worth drawing attention to is that the particular stylistic norms around the music video form are subject to a considerable amount of commercial pressure, as video-makers who want to be commercially successful are generally obliged to model their videos on MTV-style aesthetics. In other words, many music videos tend to 'look similar', particularly along genre lines. The critique here is that the spaces and places depicted in music videos are devoid of any real difference and/or locality, but instead are homogenised, abstract spaces, shaped by the dictates of capitalism.

\section{Theorising the music video}

In turning now to look at a history of the theorisation of the music video form, we can gain some sense of the ways music videos have been critically analysed, while in the process also clearing some conceptual room for an approach that addresses the audiovisual fantasy spaces of music videos from a different perspective. With the arrival of MTV, three important texts came to be published that addressed the then-new phenomenon of music video: E. Ann Kaplan's Rocking around the Clock (1987), Andrew Goodwin's Dancing in the Distraction Factory (1992), and the collection Sound and Vision: The Music Video Reader (1993), edited by Goodwin along with Simon Frith and Lawrence Grossberg. With the avenues of debate opened up by these texts, it became apparent that music video studies, involved in examining a hybrid form, was - and in many ways continues to be - caught up in a precarious balancing act between the predominant influences of film studies, television studies, and popular music studies.

Andrew Goodwin adopted the stance that the visuals in music video operate to support the soundtrack - that music video's visual aspects are secondary to 'the music itself.' Goodwin's analysis of MTV attempts to demonstrate "exactly how we might invert the position of film studies, by demonstrating exactly how the visuals support the sound track" (1992: 70). This is an oversimplification, which can be traced to his attempt to 
reclaim the music video form for popular music studies, from the film/television studies approach deployed by Kaplan, who looked at how the image had come to supersede and lay claim to the music. (This perspective has not disappeared. Saul Austerlitz opines that: "The music video marks the triumph of the visual over the oral". 2007: 1). Kaplan's Rocking around the Clock focused on the genre's fragmentary narratives and unusual forms of characterisation, viewing MTV as an almost pure realisation of Raymond Williams' notion of television as 'total flow' that fragments the subject position of the viewer. In opposition to the film/television theory trajectory, Goodwin's book, along with the anthology Sound and Vision, are firmly grounded upon a more exactingly music-centred methodology. Dickinson offers the succinct critique:

Although both the image and music figure in Goodwin's argument, he is so eager to stress the importance of the latter and to oppose Kaplan, that, again, the intrigue of music video's specific union of sound and image suffers shorter shrift than it deserves (2007: 13).

This articulation between sound and image has been neglected or underplayed by other commentators. John Corbett argues that music video is actually "a hybrid of radio and record jacket... music video establishes a domain in which radio's visual lack can be 'filled' with any set of images" (1994: 40). This is a problematic claim, and overlooks the specific characteristics of moving images paired with music. Corbett declares that "MTV is simply radio coming to grips with the overwhelming visuality of current music commodities; it exploits the association of vision with a medium long known to be merely auditory." It is therefore not surprising, Corbett continues, "that verisimilitude is not the basis for value in image/sound replenishment in music video, that the viewer need not 'believe' that the singer is actually singing." Corbett links music video with its closest cinema cousin, extra-diegetic music in narrative film (now available on soundtrack records, he quips), and remarks that "there is no assumption that the music emanates from within the pro-filmic space; the seen and the heard need not coincide in supposed unity. Rather, image and sound simply co-occur" (1994: 39-40).

John Connell and Chris Gibson adopt a related stance, commenting that: "Popular music is much more than soundtrack alone", as "images of lifestyles, places and particularly performers are enhanced (or sometimes challenged) by live performance, record and CD sleeves and music video" (2003: 84). Citing Lawrence Grossberg, they point out that "when you listened, you were also seeing the performers and other fans... styles of 
clothing... images of the sexual body... fantasies and social experiences". 6 They conclude that: "Visual images are at least as diverse as lyrics, and since the 1960s, when television and pictorial record sleeves emerged more or less contemporaneously, have acquired increasing importance" (Connell and Gibson 2003:84). While Connell and Gibson grant that visual images have acquired increasing importance, they do not sufficiently investigate the evolving relationship between music and image, which has given rise to the increasingly malleable fantasy spaces of the music video form.

Middleton and Beebe suggest that a second wave of music video studies is currently coming about, driven by three factors:

the proliferation of multiple niche-based cable and satellite channels showing music videos, the explosion of music video production and programming globally, and the advent of alternative technologies for the dissemination of music video ... these changes demonstrate a significant transformation in the culture of music video from that in which the extant body of scholarship on the form emerged (2007: 3).

As per Middleton and Beebe's suggestion, I will draw on the work of psychoanalytical film theorist Michel Chion, who has written influentially on film sound. In his work on film sound, Chion introduces the concept of 'added value', which refers to "the expressive and informative value with which a sound enriches a given image so as to create the definite impression... that this information or expression 'naturally' comes from what is seen, and is already contained in the image itself" (1994: 5). Deploying and, to a degree, reversing, Chion's notion of added value seems to be a straightforward and productive way to move beyond the image vs. sound opposition, enabling a more nuanced way to read Goodwin's prognosis that the visuals of music videos simply function to support the soundtrack.

In simple terms: the images of music videos work to offer the music an added value, whereby the images enrich a given song, by providing a visual expression that in many ways seeps into and infuses the song. The visuals do not simply support the music, but in a sense, fuse with and resonate with the music. This relates to another concept developed by Chion, the notion of 'synchresis', which is also of relevance to our examination of music video. Chion defines synchresis as "the spontaneous and

\footnotetext{
${ }^{6}$ Grossberg, 1993, p. 188; cited in Connell and Gibson, 2003, p. 84.
} 
irresistible weld produced between a particular auditory phenomenon and visual phenomenon when they occur at the same time. This join results independently of any rational logic." Chion mentions that "synchresis can even work out of thin air", and when fused together, even "images and sounds that strictly speaking have nothing to do with each other" will form "irresistible agglomerations in our perceptions" (1994: 63). In our audiovisual era, music now operates through a close relationship with image; and sound-image articulations have become naturalised, powerful, and extremely familiar aspects of our mediatised reality. Music comfortably moulds itself around the image; this articulation lends both image and music added degrees of meaning.

We have come to live in a culture of audiovisuality. We are surrounded by images and sounds on an everyday level, a situation which is facilitated by the proliferation and naturalisation of media environments. Everyday life has become interpenetrated by mass mediated images and sounds. The media have come to possess a fundamental role in the production and reception of meaning, increasingly providing the means through which we relate to, understand, and experience the world, the things within it, our place and sense of belonging within it, and the people that share it with us. As they are significant aspects of our audiovisual culture, it is necessary to realise and examine the role and pervasiveness of images, along with the role and pervasiveness of music, in our everyday life. As more and more aspects of life are coordinated through mass mediated information flows, this space of mediation is becoming increasingly important, particularly in providing us with commodities, narratives, and signs for the construction of a sense of cultural/social identity. Looking at the form and function of contemporary music video now, is to examine how music has evolved in how it is packaged and consumed, in how it is meaningful - against a backdrop of globalisation, capitalism, and transnational media flows. In our times, shaped by technological developments and concomitant social practices of production and consumption, music is, seemingly paradoxically, at once more disposable and at the same time more indispensable as a cultural commodity, as a means of articulating identity, subcultural capital (Thornton 1996), taste and belonging, as well as 'resistance'. There has been a fundamental change in what music 'is', in how we conceive and consume music - music has, to a large extent, become defined through image. 
How do music video images expand on, manipulate, fabricate, and construct the symbolic/imaginary/physical 'where' that the music 'comes' from? John Connell and Chris Gibson emphasise that

popular music is spatial - linked to particular geographical sites, bound up in our everyday perceptions of space, and a part of movements of people, products and cultures across space (2003: 1).

An integral part of cultural identity is the need to belong in and/or to a 'place', physical or not - place and identity thus have an important relationship. John Street comments: "in the business of making music, places matter" - and with the cultural practice of consuming music, places also matter. Street continues: "The unstated assumption of this rhetoric is that we cannot understand the music unless we know where - physically - it comes from" (Street 1997: 99). Of course, this 'where' is not just a physical place. We have the conclusion that music is spatial; music links onto notions of place, space, and origins - music needs to be territorialised, as Deleuze would say - how, then, has the music video operated to 'anchor' music in particular ways? In order to unpack these questions, they need to be plugged into and situated against a wider conceptual context, that of globalisation and our mass mediated, audiovisual culture. As John Thompson observes: "The reordering of space and time brought about by the development of the media is part of a broader set of processes which have transformed (and are still transforming) the modern world" (Thompson in Held and McGrew 2003: 252, 246).

Three overlapping levels can be identified where music video relates to place and space. First, music videos - as audiovisual commodity and media form occurring in a given space and time - are contained in, and part of, the interrelated, mass mediated, global space of flows. Second, and most simply, music video provides audiovisual depictions of places and spaces, and representations of how bodies and objects behave and are organised within these spaces and places. Third, the depictions and representations of music video - the fantasy spaces/places of music video - have an ideological, conceptual, and fantasmatic impact, in the sense of shaping our lived spaces, our social reality, as these imaged and imagined spaces and places produce and reproduce dispositions, habitus (Bourdieu), and modes of identification and belonging. 


\section{The fantasy spaces of music video}

In his book No Sense of Place (1985), Joshua Meyrowitz insisted that the global mass media have facilitated communities with "no sense of place" (1985). Arjun Appadurai expands on this: "The world we live in now seems rhizomatic, ${ }^{7}$ even schizophrenic, calling for theories of rootlessness, alienation, and psychological distance between individuals and groups on the one hand, and fantasies (or nightmares) of electronic propinquity on the other. Here, we are close to the central problematic of cultural processes in today's world" (1996: 29). It seems clear that due to the ongoing process we have labelled as globalisation, a sense of rootlessness is in play - which gives rise to an associated, accentuated desire to produce a heightened sense of locality, to give us a sense of belonging to a place while in living in a global village. We need to have a sense of place, we need to feel a sense of belonging - so perhaps Meyrowitz's axiom needs to be reformulated, as although we are caught up in the global space of flows (as Castells terms it) that enables 'no sense of place', we increasingly find and require a massmediated construction and re-construction of a kind of collectively imagined place/space. The importance of producing locality ${ }^{8}$ cannot be understated, in an era of globalisation and global flows, where rootlessness and the space of flows predominate. Music videos have come to produce and enable the consumption of particular imaged/imagined spaces and places, which are fused with and often indelibly associated with the music.

Henri Lefebvre provides a richly productive conceptual toolbox with regards to questions of space/place. ${ }^{9}$ Lefebvre, in his work on the production of space, posits a theory that understands space as fundamentally bound up with social reality. Space, therefore, needs to be conceived of as being simultaneously real-and-imagined. In the first chapter of The Production of Space, Lefebvre espouses his intention to develop a theory that would allow us to comprehend the three interrelated 'fields' of space physical, mental, and social - which have become artificially separated in terms of how we have come to understand space (Lefebvre 1991: 11). ${ }^{10}$ Lefebvre writes that spaces

\footnotetext{
${ }^{7}$ Deleuze and Guattari, 1987.

${ }^{8}$ I am referring to locality here as a structure of feeling, a property of social life, and an ideology of situated community.

${ }^{9}$ As will be elaborated later, these two concepts are not necessarily the same.

${ }^{10}$ Lefebvre is of the opinion that space and time are inextricably connected. Unfortunately, the issue of time and Lefebvre's project of rhythmanalysis fall largely outside the scope of this paper.
} 
considered in isolation are "mere abstractions," while they "attain 'real' existence by virtue of networks and pathways, by virtue of bunches or clusters of relationships" (1991: 86).

Instead of treating space as an independent material reality existing 'in itself', we need to examine the social relationships (Merrifield 2006: 105) that are latent in spaces, concentrating our attention on the material and conceptual production of space and the social relationships inherent to it. With Lefebvre, "space becomes reinterpreted not as a dead, inert thing or object but as organic and alive: space has a pulse, and it palpitates, flows, and collides with other spaces" (1991: 88). Various spaces, Lefebvre points out,

are traversed by myriad currents. The hyper-complexity of space should now be apparent, embracing as it does individual entities and particularities, relatively fixed points, movements, and flows and waves - some interpenetrating, others in conflict" (1991: 88).

Lefebvre offers a nuanced method of investigating space not just as a simple container, but as a complex field invested with and also in turn shaping physical, imagined, and lived relationships. Music, of course, occurs within and fills places and spaces, thereby helping to produce particular social spaces, which in turn influence specific sets of behaviours, relationships, and dispositions. Jonathan Sterne, writing about how music shapes shopping malls as social spaces (1997: 29), proposes that music can be conceived of as "one of the energy flows (such as electricity or air) which continually produce... social space" (1997: 29). Music video also produces social space in ways not always available to music alone.

To expand on this, I am going to appropriate two conceptual tools that can be utilised together: Slavoj Žižek's Lacanian definition of fantasy and Arjun Appadurai's notion of the contemporary role of imagination - where he observes that "electronic media provide resources for self-imagining as an everyday social project" (1996: 3-4). Appadurai announces that mass media technology has helped effect a key shift in the global cultural order:

In the past two decades, as the deterritorialisation of persons, images, and ideas has taken on new force... More persons throughout the world see their lives through the prisms of the possible lives offered by mass media in all their forms" (1996: 53-54). 
Appadurai elaborates that in our contemporary era, characterised by the compression of space and time and marked by the rapid mobility of people and mass media, "both viewers and images are in simultaneous circulation. Neither images nor viewers fit into circuits or audiences that are easily bound within local, national, or regional spaces". The mobile and fluid relationship "between mass-mediated events and migratory audiences" thus should be identified as a key feature of our global, modern era" (1996: $4)$.

As more and more aspects of life are coordinated through electronic information flows, the space of mediation is becoming increasingly important; after all, "all realities are communicated through symbols" (Castells 2000: 404). Appadurai asserts "that electronic media... transform the field of mass mediation because they offer new resources and new disciplines for the construction of imagined selves and imagined worlds ... these media ... compel the transformation of everyday resource" by providing "resources for experiments with self-making in all sorts of societies, for all sorts of persons" (1996: 3). Consequently, "consumption has become the principal work of late industrial society" - people "are drawn into the work of fantasy" through the daily social practice of consumption, as "nostalgia and fantasy are drawn together into a world of commodified objects" (1996: 82-83). And as Mark Poster neatly summarises: "without media the activity of consumption and the figure of the consumer do not take on their current status as major aspects of social life" (2006: 235). In consuming music video, what is 'the work of fantasy' that takes place? One answer is provided by Carol Vernallis, who writes: "Videos can provide suggestions about how to inhabit our bodies - in the bedroom, at a party, in a car, on a city street, or on a suburban lawn" (2004: 97). In many ways, music videos present fantasy worlds, which are composed of social spaces and places that contain and shape bodies, providing 'rules' for how these bodies should move, what these bodies should wear, as well as managing and organising the social relationships between various subjects in these spaces and places.

Fantasy enables an ideal image of the self as a 'meaningful' subject. Žižek notes: “At its most fundamental, fantasy tells me what I am for my others" (2005: 305). That is, fantasy gives meaning and purpose to the subject's life, and the meaning and purpose 
which makes life worth living is itself part of the fantasy. As such, people don't have fantasies; rather, they inhabit fantasy spaces of which they are a part. Žižek explains:

It is not the case that the subject knows in advance what he wants and then, when he cannot get it in reality, proceeds to obtain a hallucinatory satisfaction in fantasy. Rather, the subject originally doesn't know what he wants, and it is the role of fantasy to tell him that, to 'teach' him how to desire (2005: 304).

Žižek clarifies that "in the opposition between dream and fantasy, fantasy is on the side of reality: it is, as Lacan once said, the support that gives consistency to what we call 'reality" (1989: 44). As Žižek elucidates, the typical understanding of fantasy ('an imagined scenario representing the realisation of desire') "is therefore somewhat misleading, or at least ambiguous: in the fantasy-scene the desire is not fulfilled, 'satisfied', but constituted (given its objects, and so on) - through fantasy, we 'learn how to desire" (1989: 118). Through moving in and out of the fantasy spaces offered by music videos, we 'learn to desire' by watching how these spaces operate, by observing how bodies move and behave and interact in these spaces.

\section{Types of spaces in music videos}

It is worth keeping Žižek's definition in mind, in order to inflect Austerlitz's more mundane usage of 'fantasy'. Austerlitz writes:

Most videos take place in fantasy worlds, whether elaborate depictions of other realms, or more mundane fantasies of sexual gratification and musical pleasure. These are often less about a coherent narrative, one easily translatable into words, than an effect. Music videos seek to create atmosphere, above all - a mood, and a space, that viewers could slip into time and again. (2007: 2).

Space and place are not necessarily identical concepts. Vernallis points out that "the music video image rarely offers us a place to inhabit", as in attempting to match musical processes, it is typically always in flux:

The elaborate recording and postproduction techniques of popular music create sonic environments that almost never resemble lived spaces. Correspondingly, music video's settings, camera movement, and editing depart from ordinary lived experience. 
In order to "make a guess about how these spaces feel", Vernallis suggests, we need to "throw ourselves into a music video's environment" (2004: 110). The spaces in music video are fascinating in terms of the types of 'place' that are depicted.

Gilles Deleuze has provided an account of the emergence of 'any-spaces-whatever', which he attributes to the modern emergence of time-images, based on irrational cuts and de-linkages of images. Emancipated from the logical coordinates of action and the rational linkage of images, the unity of space, once held together by cause-and-effect movements, splinters into many disparate fragments. Any-spaces-whatever - "irrational, disconnected, aberrant, schizophrenic spaces - no longer obey laws of traditional, commonsensical causality" (Flaxman 2000: 5). For Deleuze, an any-space-whatever is "a space that does not yet appear as a real setting or is abstracted from the spatial and temporal determinations of a real setting" (Rodowick 1997: 63). It is a space which has not yet been situated. As Deleuze explains, while they are figures of indetermination, an any-space-whatever is not an abstract universal, but rather

is a perfectly singular space, which has merely lost its homogeneity, that is, the principle of its metric relations or the connection of its own parts, so that the linkages can be made in an infinite number of ways. It is a space of virtual conjunction, grasped as pure locus of the possible (Deleuze 1986: 109).

An any-space-whatever can be an emptied space, or a space whose parts are not yet linked in a given trajectory of movement. An any-space-whatever, then, "is a spatial fragment or fragments whose identity and meaning remain part of an indeterminate multiplicity that nonetheless expresses a quality or power" (Rodowick 1997: 64).

Are these any-spaces-whatever the placeless spaces typically found in many music videos? Perhaps these placeless spaces can be best conceptualised as no-places. E. Ann Kaplan had already observed that "the rock video [frequently] looks like no place, or like a post-nuclear holocaust place - without boundaries, definition or recognisable location" (1987: 145). Not only characteristic of rock videos, but also discernible in a number of other genres as well, these no-places of music video can be perhaps conceived of as ideal-places, differential spaces, or even as any-spaces-whatever, which are outside many of the rules and structures of everyday life and reality, and hence perhaps liberated to be idealised fantasy other-spaces and scenarios, places of escape, infused and shaped by music and moving bodies. However, it seems evident that these 
differential spaces in music videos can also become homogenised, conventionalised, ritualised, abstract (in Lefebvre's sense) spaces, yet another commodity produced, traded and sold as signs and nodes of cultural resistance and identity.

\section{Two music videos: Rihanna's 'Umbrella' (2007) and Jay-Z's '99 Problems' (2004)}

In Rihanna's music video for 'Umbrella' (2007, directed by Chris Applebaum), she launched a new, sexier image, underscored by a signature new hairstyle. In significant portions of the video, she is adorned only in silver body paint. Her clip - with a cameo verse and appearance by Jay- $Z$ - also featured innovative visual effects involving Rihanna dancing amidst airborne splashes of water, reminiscent of the famous bullettime sequences in The Matrix (1990), a much-commented-upon landmark in the evolution of visual special effects. Bullet-time allows the filmic illusion whereby the passage of time is dramatically slowed or frozen in order to allow a viewer to observe imperceptibly fast events (such as flying bullets). In a well-known sequence in The Matrix, as time slows to a crawl, we can observe Neo arc his body in seemingly impossible positions to dodge bullets being fired at him, which come towards him in tantalising slow-motion, trailing slipstreams in their wake. As Pierson describes, it is

a technique used for creating the illusion of movement around objects in the foreground. In defiance of the natural laws of cinematography, elements of the filming could be made to appear to be moving at different speeds, with higherspeed camera moves miraculously tracking slow-motion action scenes (2002: 163).

In 'Umbrella', Rihanna dances in between slow-motion mercury-like splashes of water, flicking them into different directions as she moves to the music. The video takes place in a number of locations, but these locations can be categorised as no-places. As Vernallis notes:

The locations that appear most often in music video tend to be generic depictions, suggesting a concept of place, or representing a kind of place, rather than providing a detailed description of a specific setting (2004: 75).

Settings can provide a quick way for viewers to identify what genre a song belongs to. In this case, the smooth glossy surfaces and textures of the spaces seem to reflect the 
high-end production values of contemporary R\&B. As Vernallis elaborates: "Settings can serve different functions, such as making social points, showing the artist's status in some community, foregrounding musical features, or highlighting production practices" (2004: 76). However, these representations can accumulate and become overbearing stereotypes. "Not only the settings themselves, but also the use of space, props, and especially the disposition of figures, become problematic. And it has as much to do with the absence of certain kinds of representation as with what we do see" (2004: 73-74). In this sense, these imaged-imagined spaces can operate to influence and produce specific sets of behaviours, relationships, and dispositions.

One of the most common and problematic features of the spaces/places presented by music videos is the way women are 'naturally' depicted and expected to act as sexualised objects. "In music video, the primary role of women is to serve as eye candy," Austerlitz notes, and the "presence of half-nude women in the background (and foreground) of practically every music video ever made has grown so commonplace that it appears almost unworthy of attention." In fact, "any deviation is seen as a variation from the norm." He adds that when women are the performers, then theirs is "the body to be ogled". This is certainly true for Rihanna's video, which served to give her career added impetus by re-imagining and re-presenting the sexuality of her performance persona. For the most part, Austerlitz argues, music videos

are intended for men's eyes, providing them with endless opportunities to delectate in the spectacle of beautiful women performing for their pleasure. Videos are male fantasies of controlling and possessing women, and to avoid this subject is to miss one of the most fundamental aspects of music video (2007: 4).

Returning to Lefebvre: we need to examine the social relationships that are latent in spaces, concentrating our attention on the (material and conceptual) production of space and the social relationships inherent to it.

Place is depicted another way in Jay-Z's music video for '99 Problems' (2004, directed by Mark Romanek). The clip - which won a number of awards - is shot in black-andwhite, and is set primarily in Brooklyn, New York. Jay-Z - as well as other supporting characters (including Rick Rubin, the song's producer) - moves comfortably through and is framed within/against neighbourhood spaces, buildings, and streets which he and the others appear intimately familiar with. Some of the things we see are the Marcy 
Houses housing project where Jay- $Z$ grew up, Jay- $Z$ on the Brooklyn Bridge, Jay- $Z$ performing in a small club, interspersed with shots of basketball players on a court, break dancers breaking on the side of a street, a choreographed dance routine by a small group of men, inmates in a prison in the Bronx, a rabbi praying, a funeral director making his preparations, and the seemingly obligatory sequences of scantily clad women. We also see Jay-Z and Rubin driving in a car, and being stopped by police. The controversial and climatic final scene depicts Jay-Z being shot in stylised slow-motion with a hail of bullets by unseen assailants, symbolically marking the 'death' (retirement) of his Jay-Z persona, as the album from which the song is taken (The Black Album, 2003) was meant to be Jay-Z's final studio album. ${ }^{11}$

The video's director, Mark Romanek, has built a reputation as one of the most subtle architects of video space. The video presents a 'real' place - Brooklyn. And indeed, hiphop is a genre that is particularly invested in creating a sense of place, where hip-hop videos frequently "feature identifiable housing projects, small businesses, and street signs. Even if one is unfamiliar with a location, one senses that its particularity matters." As Vernallis concludes, it is often even possible to "pick out the difference between East Coast and West Coast videos through architecture and quality of light" (2004: 78). In these videos, not only does place matter, but the relationship between place and performer is also important: the performers appear to belong to the place. Connell and Gibson (citing Pratt) remark that for many hip-hop songs,

there is a powerful evocation that music of the kinds they perform is originally rooted in some place or authentic locale where an audience of real people, preferably including blacks, are depicted as enjoying it (2003: 85).

The places in Brooklyn that are depicted are real-and-imagined, functioning on the level of myth, operating on the level of fantasy (as Žižek would define it), produced and framed as particular physical, imagined, and lived spaces/places (as theorised by Lefebvre), set in service to the music, operating to lend added value and emotional resonance to the music.

In many ways, the images of music video can be compared to the ways in which film music works - this analogy can be related to the video for '99 Problems'. I am making

\footnotetext{
${ }^{11}$ He subsequently announced a return to his recording career in 2006.
} 
this comparison to bring out several features of music video imagery - I am certainly not saying that these are simply interchangeable. Film music is generally acknowledged to act as a vector, (see Chion 1994: 18-20), anchoring the flow of images and offering a set of viewing instructions for images that it accompanies. The images of music video anchor the music in spaces and places, providing and fleshing out characters and scenarios, offering a set of listening instructions for the music that it accompanies. Heard in isolation, film scores often don't make much musical sense; the music is deliberately written to enhance the mood of a scene and to underscore the action, not as a foreground activity, but as a background one. The images of music video do not really adhere to traditional narrative structures; the images are deliberately placed to articulate with the music. The function of film music is to 'tell' the audience how to feel, from moment to moment. The images of music video often function to 'tell' listeners how to interpret a song. Royal Brown argues that film music, as a non-iconic medium, when accompanying the other tracks of film, can have a generalising function, encouraging the spectator to receive the scene on the level of myth, while also triggering a 'field of association' likely to foster emotional identification. ${ }^{12}$ Music video imagery can also trigger a 'field of association' capable of fostering emotional identification, while also encouraging certain receptivity - by creating fantasy worlds, and a mood and a space so that viewers/listeners can fall into the narrative/s within the song.

\section{Music, images, spaces, bodies}

In thinking about music video as a specific cultural commodity which helps provide us with "a way of perceiving the world" (Attali 1985: 4), and helps supply us with "a cultural 'map of meaning', [which can be used] to locate [ourselves] in different imaginary geographies... and to articulate both individual and collective identities" (Cohen 1998: 286-287) - does music video operate as means of expressing and fertilising cultural resistance, or as culture industry? A postmodern reading of music videos - focusing on their visual, fragmentary, and intertextual nature - is typically used to argue that the form is a means of subversive expression. The work of Michel de

\footnotetext{
${ }^{12}$ Royal S. Brown, 1994; more generally, Brown notes that (non-diegetic) film music functions on at least three levels: as "wallpaper soporific" to allay fears of the dark or silence and to hide noises elsewhere, as an "aesthetic counterbalance to the iconic/representational nature of the cinematic signs", and as a "cogenerator of narrative affect". (p. 32.) Brown adds that we cannot ignore the manipulative aspect of film music. (p. 110.)
} 
Certeau is often drawn on to articulate theories of cultural resistance. De Certeau famously argues for the celebration of everyday life as the realm of 'resistance' par excellence. In his The Practice of Everyday Life (1984), he suggests that resistance is enacted through 'walking, reading, decorating, cooking' (and don't forget watching music videos!), and so on; that is, in the realm of 'creative consumption' rather than production, making it easier for not only resourceful subalterns but members of the intellectual establishment to join in the 'transgression' of something. ${ }^{13}$

De Certeau offers an attractive alternative to the notion of the passive consumer of culture - however, his inflation of 'resistance' simply elides and appears to wish away many of the complex questions that need to be addressed regarding notions of ideology, hegemony, and the culture industry. Theodor Adorno's infamous account of the culture industry is all too frequently caricatured as a one-dimensional indictment of consumers as passive victims. However, a more careful examination reveals that Adorno's analysis of the culture industry's consumers by no means regards them as inert victims. Rather, the culture industry could not be so successful without the avid participation of consumers.

Adorno emphasises the extent to which cultural consumption has become sheer hard work - the culture industry is a 'constant initiation rite'. ${ }^{14}$ As Simon Jarvis clarifies:

The energetic participation of consumers in the culture industry testifies not to their foolishness but to their well-founded sense that they will be punished with social exclusion for a failure to keep up with cultural production (1998:75).

Music videos are increasingly and typically geared towards the manufacturing and selling of symbols and tropes of subcultural capital, as well as resistance. So to suggest that music videos (and pop music) act as a straightforward means of resistance is naïve. Music videos have predictable musical forms, and have increasingly become commodified and a mere sign of resistance. Music television has become a powerful force of consolidation, rather than diversity, within the industry.

\footnotetext{
${ }^{13}$ See, for example, Chapter III, “"Making Do": Uses and Tactics', 1984, pp. 29-42.

${ }^{14}$ See Horkheimer and Adorno, 1973, p. 167.
} 
In order to examine, as Cohen puts it, "the ways in which music is used and the important role that it plays in everyday life and in society generally" (1993: 127), I have suggested that it is productive to examine music video in terms of mapping how the music video form produces and circulates real-and-imagined spaces/places and bodies/subjectivities for our consumption. The development of music clips represents a general shift in power, where record companies and media conglomerates tend to have the upper hand in terms of visualising music, instead of the musicians. However, music videos should not be generalised. MTV - and many of the channels which show music videos - is certainly commercial and manipulative, but to simply suggest that pop music has 'sold out' is naïve. Pop was always commercial. It is important to observe that music videos are simultaneously involved in the incorporation and the promotion of dissent. Appadurai also disagrees with "the theory of media as the opium of the people". However, as he makes clear, it is important to emphasise that consumers are not simply "free agents, living happily in a world of safe malls, free lunches, and quick fixes." Rather,

consumption in the contemporary world is often a form of drudgery, part of the capitalist civilising process. Nevertheless, where there is consumption there is pleasure, and where there is pleasure there is agency.

For Appadurai, the mass media has come to play an important role in making possible a 'community of sentiment', "a group that begins to imagine and feel things together ... Collective experiences of the mass media, especially film and video, can create sodalities of worship and charisma" (Appadurai 1996: 5-8). After all, we have come to use mass media commodities as our means of communication with each other, as ways to help construct and communicate our sense of identity and subjectivity.

\section{Bibliography}

Appadurai, A. (1996) Modernity at Large: Cultural Dimensions of Globalization, Minneapolis: University of Minnesota Press.

Attali, J. (1999) Noise: The Political Economy of Music, translated by Brian Massumi, with Foreword by Fredric Jameson and Afterword by Susan McClary, Minneapolis: University of Minnesota Press.

Austerlitz, S. (2007) Money for Nothing: A History of the Music Video from the Beatles to the White Stripes, New York and London: Continuum. 
Beebe, R. (2007) 'Paradoxes of Pastiche: Spike Jonze, Hype Williams, and the Race of the Postmodern Auteur', in Beebe, R. and Middleton, J. (eds) Medium Cool: Music Videos from Soundies to Cellphones, Durham and London: Duke University Press, 303-327.

Brown, R. S. (1994) Overtones and Undertones: Reading Film Music, Berkeley: University of California Press.

Castells, M. (2000) The Rise of the Network Society, $2^{\text {nd }}$ Edition, Oxford and Cambridge, Massachusetts: Blackwell.

Chanan, M. (1995) Repeated Takes: A Short History of Recording and Its Effects on Music, London: Verso.

Chion, M. (1994) Audio-Vision: Sound on Screen, translated by Claudia Gorbman, New York: Columbia University Press.

(1999) The Voice in Cinema, translated by Claudia Gorbman, New York: Columbia University Press.

Cohen, S. (1993) 'Ethnography and Popular Music Studies', Popular Music 12 (2), 123138.

(1998) 'Sounding out the City: Music and the Sensuous Production of Place', in The Place of Music, edited by Andrew Leyshon, David Matless, and George Revill, London: The Guildford Press.

Connell, J. and Gibson, C. (2003) Sound Tracks: Popular music, identity and place, London: Routledge.

Corbett, J. (1994) Extended Play: Sounding Off From John Cage to Dr. Funkenstein, Durham and London: Duke University Press.

De Certeau, M. (1984) The Practice of Everyday Life, translated by Steven F. Rendall, Berkeley: University of California Press.

Deleuze, G. (1986) Cinema 1: The Movement-Image, translated by H. Tomlinson and B. Habberjam, Minneapolis: University of Minnesota Press.

Deleuze, G. and Guattari, F. (1987) A Thousand Plateaus: Capitalism and Schizophrenia, translated by Brian Massumi, Minneapolis: University of Minnesota Press.

DeNora, T. (2000) Music in Everyday Life, Cambridge: Cambridge University Press.

Dickinson, K. (2007) 'Music Video and Synaesthetic Possibility', in Beebe and Middleton, 13-29.

Flaxman, G. (ed.) (2000) The Brain is the Screen: Deleuze and the Philosophy of Cinema, Minneapolis: University of Minnesota Press.

Frith, S. Goodwin, A. and Grossberg, L. (eds). (1993) Sound and Vision: The Music Video Reader, London: Routledge.

Goodwin, A. (1992) Dancing in the Distraction Factory: Music Television and Popular Culture, Minneapolis: University of Minnesota Press.

Grossberg, L. (1993) 'The Media Economy of Rock Culture: Cinema, Post-Modernity and Authenticity', in Frith, Goodwin, and Grossberg, 185-209. 
Gunning, T. (1990) 'The Cinema of Attractions: Early Film, Its Spectator, and the Avant-Garde', in Elsaesser, T. and A. Barker (eds.) Early Cinema: Space, Frame, Narrative, London: BFI, 1990.

Horkheimer, M. and Adorno, T.W. (1973) Dialectic of Enlightenment, translated by John Cumming, New York: Continuum.

Jarvis, S. (1998) Adorno: A Critical Introduction, Cambridge: Polity Press.

Kaplan, E. A. (1987) Rocking around the Clock: Music Television, Postmodernism and Consumer Culture, Oxford: Blackwell.

Katz, M. (2004) Capturing Sound: How Technology Has Changed Music, Berkeley and Los Angeles: University of California Press.

Lefebvre, H. (1991) The Production of Space, translated by Donald Nicholson-Smith, Oxford: Blackwell.

Leppert, R. (1993) The Sight of Sound: Music, Representation, and the History of the Body, Berkeley and Los Angeles: University of California Press.

Lewis, L. (1990) Gender Politics and MTV, Philadelphia: Temple University Press.

Merrifield, A. (2006) Henri Lefebvre: A Critical Introduction, New York and London: Routledge.

Mulvey, L. (1975) 'Visual Pleasure and Narrative Cinema', Screen, 16, 3, Autumn.

Pierson, M. (2002) Special Effects: Still in Search of Wonder, New York: Columbia University Press.

Poster, Mark, 2006, Information Please: Culture and Politics in the Age of Digital Machines, Durham and London: Duke University Press

Pratt, R. (1990) Rhythm and Resistance: Explorations in the Political Use of Popular Music, New York: Praeger.

Rodowick, D.N. (1997) Gilles Deleuze's Time Machine, Durham and New York: Duke University Press.

Sterne, J. (1997) 'Sounds Like the Mall of America', Ethnomusicology, 41, 22-50.

Street, J. (1997) Politics and Popular Culture, Cambridge: Polity Press.

Thompson, J.B. (2003) 'The Globalization of Communication', in Held, D. and A. McGrew (eds). The Global Transformations Reader: An Introduction to the Globalization Debate, Second Edition, Cambridge: Polity Press.

Thornton, S. (1996) Club Cultures: Music, Media, and Subcultural Capital, Middletown: Wesleyan University Press.

Vernallis, C. (2004) Experiencing Music Video: Aesthetics and Cultural Context, New York: Columbia University Press.

(2007) 'Strange People, Weird Objects: The Nature of Narrativity, Character, and Editing in Music Videos', in Beebe and Middleton, (eds) Medium Cool: Music Videos from Soundies to Cellphones, Durham and London: Duke University Press, 111-151.

Žižek, S. (1989) The Sublime Object of Ideology, London and New York: Verso.

(1996) 'Lacan in Slovenia', interview with Renata Salecl, in Osborne, P. (ed.) A Critical Sense: Interviews with Intellectuals, London: Routledge, 21-35. 
(2005) 'Re-visioning 'Lacanian' Social Criticism', in Butler, R. \& Stephens, S. (eds.) Interrogating the Real, London and New York: Continuum. 